Check for updates

Cite this: Mater. Chem. Front., 2019, 3, 1449

Received 18th April 2019, Accepted 14th May 2019

DOI: $10.1039 /$ c9qm00252a

rsc.li/frontiers-materials

\title{
Polymer-grafted gold nanoflowers with temperature-controlled catalytic features by in situ particle growth and polymerization $\dagger$
}

\author{
Chaojian Chen, (D) ${ }^{\text {ab }}$ David Yuen Wah Ng (D) $\star^{a}$ and Tanja Weil (D) $\star^{a b}$
}

\begin{abstract}
We report a convenient strategy for the synthesis of polymer-grafted gold nanoflowers by combining an activator regenerated by electron transfer atom transfer radical polymerization (ARGET ATRP) and the reduction of metal ions in a one-pot fashion. Poly( $N$-isopropylacrylamide)-coated gold nanoflowers (PNIPAM-AuNFs) with controllable sizes, shapes, and shell thickness are obtained and applied as temperature-controlled nanoparticle catalysts for the hydrogenation of $p$-nitrophenol.
\end{abstract}

Polymer-metal hybrid nanomaterials, particularly polymergold nanocomposites, have attracted continuous attention over the past two decades. ${ }^{1,2}$ The combination of chemical, optical, and electronic characteristics of nano-sized metals with tunable features of functional polymers has opened various promising applications including as components in optical and electronic devices, as well as in catalysis, sensors and biomedicine. ${ }^{3,4}$ It is widely accepted that the properties of polymer-metal nanocomposites are largely determined by their composition, shape, size, distribution, and surface structures. Therefore, substantial efforts have been devoted to control and optimize the properties of these nanomaterials. ${ }^{5,6}$

Gold nanoflowers (AuNFs) are unique nanostructures with large numbers of branches. ${ }^{7-10}$ Owning to their coarse surfaces consisting of many sharp tips, as well as high surface-to-volume ratios, 3D hierarchical AuNFs have demonstrated remarkable performances in catalysis, ${ }^{11,12}$ surface-enhanced Raman scattering, ${ }^{13-15}$ photothermal conversion, ${ }^{16}$ and cell imaging. ${ }^{17}$ AuNFs with surface-grafted functional polymers are particularly attractive as the polymer shell provides additional features such as solubility and stimuli-responsiveness. ${ }^{18}$ Polymer-AuNFs can be achieved by in situ reduction of gold ions in the presence of polymer templates or by grafting polymer chains to or from already formed AuNFs. ${ }^{19}$ However, these methods involve tedious multistep fabrication and purification processes, and there is only limited control over the structure of the metal nanoparticles and the polymers at the surface. ${ }^{14}$ Therefore, a

\footnotetext{
${ }^{a}$ Max Planck Institute for Polymer Research, Ackermannweg 10, 55128 Mainz, Germany.E-mail:weil@mpip-mainz.mpg.de, david.ng@mpip-mainz.mpg.de

${ }^{b}$ Ulm University, Albert-Einstein-Allee 11, 89081 Ulm, Germany.

E-mail: tanja.weil@uni-ulm.de

$\dagger$ Electronic supplementary information (ESI) available: Experimental details, MALDIToF spectra, TEM images and other characterizations of PNIPAM-AuNFs, comparison of the catalytic activity. See DOI: 10.1039/c9qm00252a
}

facile and green route for the synthesis of multifunctional polymer-coated AuNFs would be very attractive.

Atom transfer radical polymerization (ATRP) is a widely used polymerization technique for the synthesis of well-defined polymers. However, ATRP catalysts are usually sensitive to air and other oxidants. To solve this limitation, Matyjaszewski et al. have developed an improved technique termed activator regenerated by electron transfer (ARGET) ATRP (Fig. 1A). ${ }^{20-23}$ Transition metal complexes in their oxidation stable state (e.g., $\mathrm{CuBr}_{2} /$ ligand) are used as catalyst precursors in ARGET ATRP. A reducing agent such as ascorbic acid is continuously added to reduce the $\mathrm{Cu}^{\mathrm{II}}$ species to the active catalyst ( $\mathrm{Cu}^{\mathrm{I}}$ species). The major benefits of ARGET ATRP are low amounts of catalysts, ease of preparation, storage, and handling of the ATRP catalysts in air.

We report a convenient procedure for the synthesis of catalytically active AuNFs coated by a responsive poly( $N$-isopropylacrylamide) (PNIPAM) shell by combining ARGET ATRP and the reduction of metal ions in one reaction step. The approach is based on a protein-derived biopolymer template providing (1) distinct numbers of amino groups able to bind chloroauric anions and (2) many initiation sites for ARGET ATRP. Human serum albumin (HSA) has been selected as biotemplate as it is an important physiological transporter for various metal ions ${ }^{24}$ and metallodrugs $^{25}$ in the bloodstream. In our previous work, denatured HSA has been exploited for the stabilization of metal colloids and nanoparticles. ${ }^{26-28}$ Herein, the HSA-derived biopolymer is equipped with ATRP initiators and combined with ascorbic acid reducing the metal ions and activating the ATRP catalyst for PNIPAM polymerization. In this way, PNIPAM-coated gold nanoflowers (PNIPAM-AuNFs) of tunable sizes and shapes with excellent stability and thermo-responsiveness have been obtained in a onepot reaction. Temperature-responsive PNIPAM has been used for the first time to coat AuNFs, although some PNIPAM-Au nanocomposites are known. ${ }^{29-31}$ PNIPAM-AuNFs serve as a smart catalyst, 
A

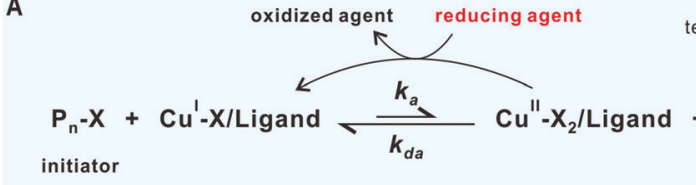

B concurrent ARGET ATRP and gold reduction.

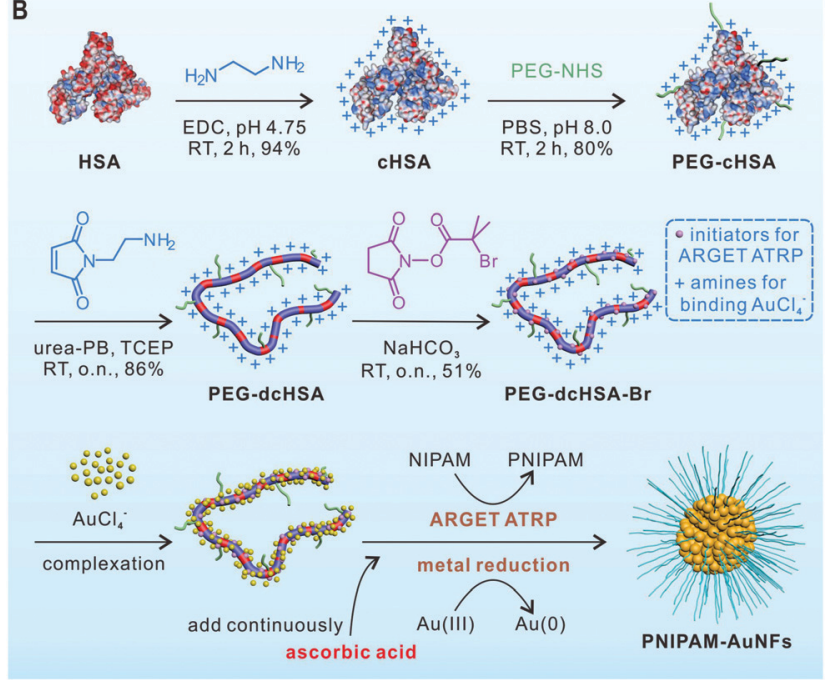

Fig. 1 (A) The mechanism of ARGET ATRP. (B) Synthesis of PEG-dcHSA-Br and its application as a substrate for preparing PNIPAM-AuNFs by one-pot

whereby the temperature-responsive PNIPAM shell controls hydrogenation of $p$-nitrophenol to $p$-aminophenol. We believe that the approach could be extended to other noble metal nanoparticles and functional polymers, providing access to a variety of multifunctional polymer-metal hybrid nanomaterials.

The synthesis of the biopolymer template is schematically illustrated in Fig. 1B. First, the carboxylic acid groups of HSA are converted into amino groups by applying a large excess of ethylenediamine to afford cationized HSA (cHSA). cHSA possesses many amino groups for the attachment of ATRP initiators and facilitates the adsorption of higher amounts of $\mathrm{AuCl}_{4}{ }^{-}$anions. To improve protein solubility and stability, short polyethylene glycol $\left(\right.$ PEG, $M_{\mathrm{n}} \sim 2000$ ) chains are conjugated to cHSA to afford PEGcHSA with about 32 PEG chains as calculated from the matrixassisted laser desorption/ionization time-of-flight (MALDI-ToF) mass spectrum (Fig. S3, ESI $\dagger$ ). Next, PEG-cHSA is denatured in urea-phosphate buffer using tris(2-carboxyethyl) phosphine hydrochloride as reducing agent. $N$-(2-aminoethyl)maleimide trifluoroacetate salt $\left(\mathrm{MI}-\mathrm{NH}_{2}\right)$ is added to cap the thiol groups generated after reduction of disulfide bridges of HSA. The resulting denatured polypeptide (PEG-dcHSA) is reacted with 2-bromoisobutanoic acid $N$-hydroxysuccinimide ester, which introduces ATRP initiators with bromide end groups to the polypeptide backbone giving PEG-cHSA-Br in 51\% yield. According to MALDI-ToF mass spectra in Fig. S4 and S5 (ESI†), 61 initiation sites per polypeptide backbone have been introduced.

For the preparation of the polymer-grafted AuNFs in one reaction pot, chloroauric acid $\left(\mathrm{HAuCl}_{4}\right)$ is selected as the metal
Table 1 Synthesis of PNIPAM-AuNFs under different conditions

\begin{tabular}{lllll}
\hline Entry & Molar ratio of $-\mathrm{NH}_{2} / \mathrm{HAuCl}_{4}$ & $T^{a}\left({ }^{\circ} \mathrm{C}\right)$ & $t^{b}(\mathrm{~h})$ & Diameter ${ }^{c}(\mathrm{~nm})$ \\
\hline 1 & $6: 1$ & 23 & 2 & $148 \pm 16$ \\
2 & $3: 1$ & 23 & 2 & $219 \pm 21$ \\
3 & $1: 1$ & 23 & 2 & $179 \pm 88$ \\
4 & $3: 1$ & 40 & 2 & $61 \pm 9$ \\
5 & $3: 1$ & 23 & 1 & $217 \pm 18$ \\
6 & $3: 1$ & 23 & 4 & $214 \pm 21$
\end{tabular}

${ }^{a}$ Reaction temperature. ${ }^{b}$ Reaction time. ${ }^{c}$ Average diameter determined from TEM images using ImageJ software.

source and $N$-isopropylacrylamide (NIPAM) as monomer to impart a thermal-responsive polymer. In a typical process, the substrate PEG-dcHSA-Br, the monomer NIPAM, the $\mathrm{HAuCl}_{4}$ solution, and the stock solution of copper(II) bromide/tris(2-pyridylmethyl)amine $\left(\mathrm{Cu}^{\mathrm{II}} \mathrm{Br}_{2} / \mathrm{TPMA}\right)$ are first dissolved in deionized water. Oxygen is removed through three freeze-pumpthaw cycles, and the solution is stirred at room temperature for one hour to allow the complexation of $\mathrm{AuCl}_{4}{ }^{-}$by the amino groups of the peptide chains. Degassed ascorbic acid solution is added via a syringe pump at a slow speed of $0.6 \mu \mathrm{L} \mathrm{min}{ }^{-1}$, and the reaction proceeds at predetermined time and temperature. Purification of the polymer-grafted AuNFs proceeds by simple centrifugation to remove unreacted monomers. As summarized in Table 1, six reaction conditions have been applied to study the impact of the $-\mathrm{NH}_{2} / \mathrm{HAuCl}_{4}$ molar ratio ( $-\mathrm{NH}_{2}$ refers to total amount of amino groups from PEG-dcHSA-Br in the reaction solution which is $300 \mathrm{nmol}$ ), reaction temperature and reaction time on the sizes and morphologies of the formed PNIPAM-AuNFs. The obtained AuNFs were imaged by transmission electron microscopy (TEM) and the results are shown in Fig. 2 and Fig. S6-S11 (ESI †).

As shown in Fig. 2A-D, AuNFs with rough surfaces are formed, and the enlarged TEM images in Fig. 2 and Fig. S6-S11 (ESI $\dagger$ ) even capture the polymer shells surrounding the AuNFs. Next, the impact of the $-\mathrm{NH}_{2} / \mathrm{HAuCl}_{4}$ molar ratio on the size and shape of PNIPAM-AuNFs is analyzed. By increasing the amount of $\mathrm{HAuCl}_{4}$ in the reaction mixture, the $-\mathrm{NH}_{2} / \mathrm{HAuCl}_{4}$ molar ratio changes from $6: 1$ (entry 1) to $3: 1$ (entry 2), and to $1: 1$ (entry 3) (Table 1, $23{ }^{\circ} \mathrm{C}, 2 \mathrm{~h}$ reaction time). The diameter of the AuNFs increased from $148 \pm 16 \mathrm{~nm}$ to $219 \pm 21 \mathrm{~nm}$ by varying the molar ratio from $6: 1$ to $3: 1$. At equimolar ratio of $-\mathrm{NH}_{2} / \mathrm{HAuCl}_{4}$ (entry 3), irregular AuNFs with more dispersed shapes are observed (Fig. 2C and Fig. S8, ESI $\dagger$ ). Here, most likely, the number of primary amines from the template is not sufficient to complex the available $\mathrm{AuCl}_{4}{ }^{-}$in solution and the biopolymer is not able to stabilize the resulting AuNFs well.

The reaction temperature also plays a crucial role for the formation of PNIPAM-AuNFs. At $-\mathrm{NH}_{2} / \mathrm{HAuCl}_{4}$ molar ratio of $3: 1$, a temperature shift from $23{ }^{\circ} \mathrm{C}$ to $40{ }^{\circ} \mathrm{C}$ results in the formation of much smaller AuNFs with an average diameter of only $61 \pm 9 \mathrm{~nm}$ (Fig. 2D-F and Fig. S9, ESI $\dagger$ ) compared to $219 \pm$ $21 \mathrm{~nm}$ at $23{ }^{\circ} \mathrm{C}$. The temperature-controlled AuNF growth is attributed to the thermal-responsive characteristics of the PNIPAM shell at the AuNFs surface. Below $23{ }^{\circ} \mathrm{C}$, PNIPAM remains well soluble in water. Therefore, gold ions and nanoclusters can penetrate the PNIPAM shell, aggregate and form larger gold 


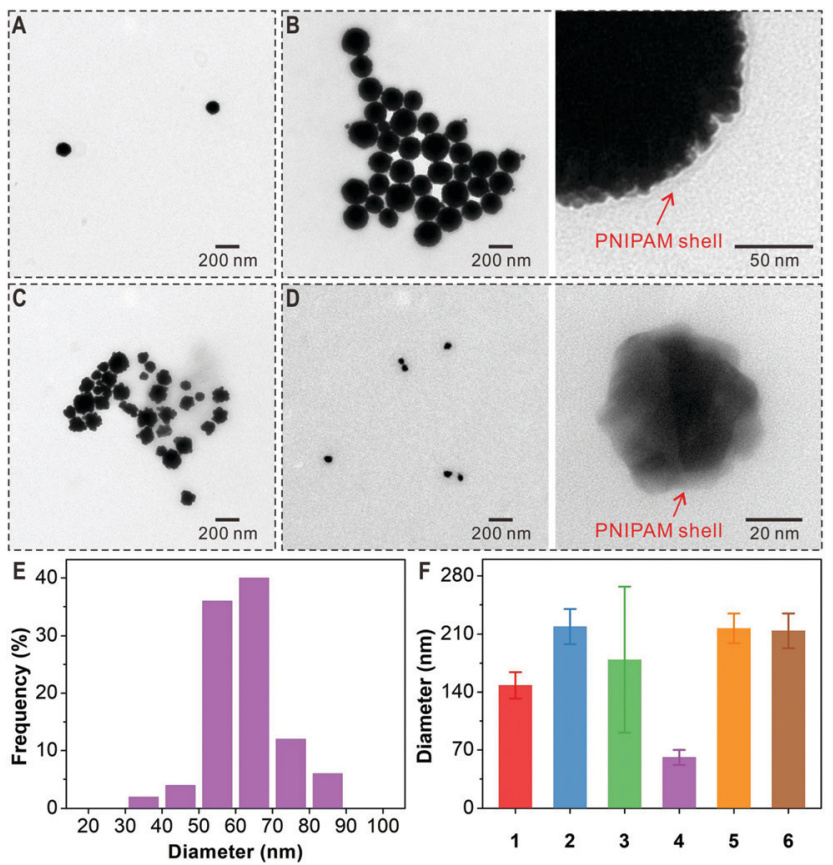

Fig. 2 TEM characterization of PNIPAM-AuNFs prepared under different conditions: (A) $-\mathrm{NH}_{2} / \mathrm{HAuCl}_{4} 6: 1,23^{\circ} \mathrm{C}, 2 \mathrm{~h}$; (B) $-\mathrm{NH}_{2} / \mathrm{HAuCl}_{4} 3: 1,23^{\circ} \mathrm{C}$, $2 \mathrm{~h}$; (C) $-\mathrm{NH}_{2} / \mathrm{HAuCl}_{4} 1: 1,23{ }^{\circ} \mathrm{C}, 2 \mathrm{~h}$; (D) $-\mathrm{NH}_{2} / \mathrm{HAuCl}_{4} 3: 1,40{ }^{\circ} \mathrm{C}, 2$ h; (E) size distribution of PNIPAM-AuNFs (entry 4); (F) the average diameters of PNIPAM-AuNFs (entries 1-6, Table 1).

nanoparticles. However, when the temperature is increased above the lower critical solution temperature (LCST) of PNIPAM, i.e. to $40{ }^{\circ} \mathrm{C}$, the PNIPAM chains collapse and form a dense shell preventing further growth of the AuNFs. Therefore, AuNF formation can be controlled in situ during the polymerization process by simply adjusting the temperature.

Varying the reaction time from $1 \mathrm{~h}$ to $2 \mathrm{~h}$ and $4 \mathrm{~h}$ does not affect the size and morphology of AuNFs and only a slight impact on the thickness of the PNIPAM shell is observed as depicted in the TEM images in Fig. S10 and S11 (ESI $\dagger$ ). In these experiments, a $-\mathrm{NH}_{2} / \mathrm{HAuCl}_{4}$ molar ratio of $3: 1$ and a reaction temperature of $23{ }^{\circ} \mathrm{C}$ are selected indicating that AuNF formation is already completed within $1 \mathrm{~h}$ reaction time.

The thermo-responsiveness of the PNIPAM-AuNFs is studied by dynamic light scattering (DLS). The hydrodynamic radius of PNIPAM-AuNFs is monitored during temperature increase from $20{ }^{\circ} \mathrm{C}$ to $60{ }^{\circ} \mathrm{C}$ with $5{ }^{\circ} \mathrm{C}$ increments (Fig. 3 and Table S1, ESI $\dagger$ ). When the temperature is kept below $30{ }^{\circ} \mathrm{C}$, the hydrodynamic radius $\left(R_{\mathrm{h}}\right)$ of PNIPAM-AuNFs remains constant within the range of $52-60 \mathrm{~nm}$. However, $R_{\mathrm{h}}$ reveals a pronounced drop to less than $30 \mathrm{~nm}$ when the temperature increases from $30{ }^{\circ} \mathrm{C}$ to $35{ }^{\circ} \mathrm{C}$. The sizes of PNIPAM-AuNFs above $30{ }^{\circ} \mathrm{C}$ correlate to the dimensions measured by TEM as depicted in Fig. 2D. Also, the transition temperature is consistent with the LCST of PNIPAM $\left(32{ }^{\circ} \mathrm{C}\right)$ reported in the literature. ${ }^{29,32,33}$ During the experiment, the solution turns slightly turbid when the temperature increases above the LCST, indicating the formation of some minor aggregates of PNIPAM-AuNFs. This is probably the reason for the size increase when the temperature rises from $40{ }^{\circ} \mathrm{C}$ to $60^{\circ} \mathrm{C}$ (Fig. 3).

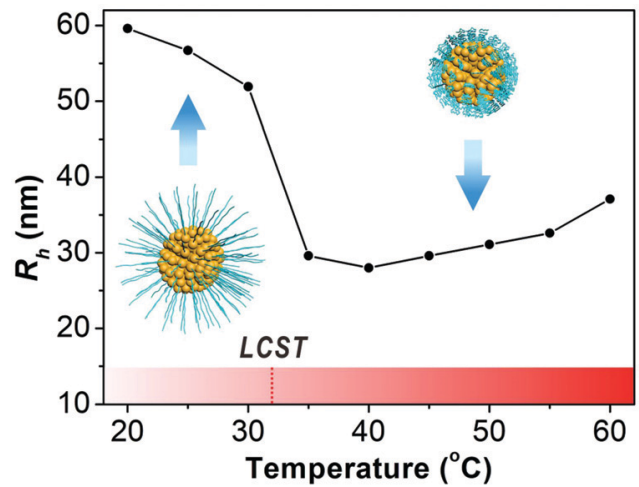

Fig. 3 Hydrodynamic radius of PNIPAM-AuNFs (entry 4) determined by DLS at increased temperature from $20{ }^{\circ} \mathrm{C}$ to $60^{\circ} \mathrm{C}$.

However, the nanohybrids can be easily re-dispersed by shaking at room temperature and the solution becomes transparent again.

PNIPAM-AuNFs with rough surfaces and a thermo-responsive polymer shell could serve as smart catalysts. As a proof of concept, the catalytic performance of PNIPAM-AuNFs is analyzed at different temperatures for the well-known hydrogenation reaction of $p$-nitrophenol to $p$-aminophenol. ${ }^{3-36}$ This reaction allows monitoring the catalytic activity of noble metal-based nanomaterials by UV-vis spectroscopy. ${ }^{37,38}$ Fig. 4 compares the catalytic properties of PNIPAM-AuNFs (entry 4) for the reduction of $p$-nitrophenol in the presence of $\mathrm{NaBH}_{4}$ at different temperatures. At $23{ }^{\circ} \mathrm{C}$, after PNIPAM-AuNFs have been added to the reaction solution, the characteristic peak of $p$-nitrophenol decreases gradually within 50 min reaction time (Fig. 4A). During this process, the solution changes from yellow to colorless. As a control, no absorption changes are observed after mixing $\mathrm{NaBH}_{4}$ and $p$-nitrophenol for $2 \mathrm{~h}$ in the absence of PNIPAM-AuNFs (Fig. S13, ESI $\dagger$ ). These results support that the PNIPAM-AuNFs possess
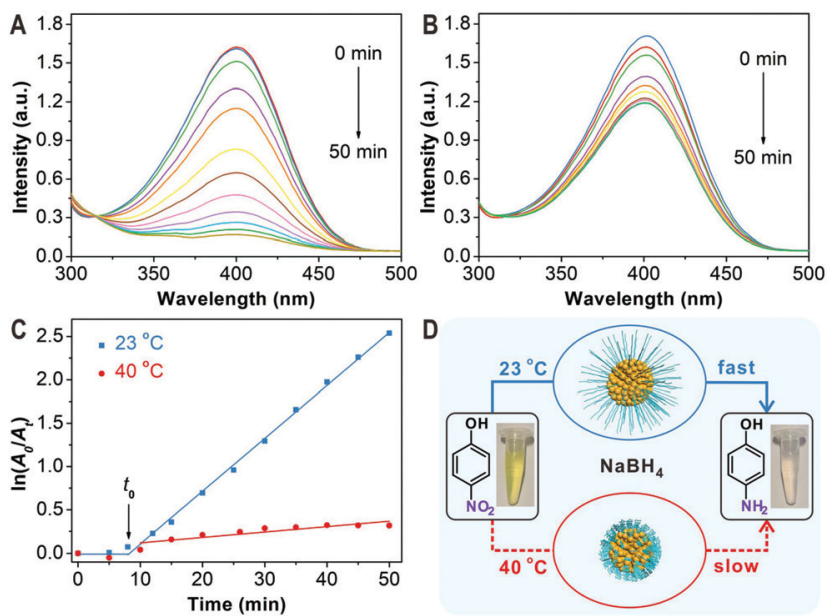

Fig. 4 Temperature-controlled catalysis by PNIPAM-AuNFs. (A and B) UV-vis spectra of the reaction solution for the hydrogenation of $p$-nitrophenol at $23{ }^{\circ} \mathrm{C}(\mathrm{A})$ and $40^{\circ} \mathrm{C}$ (B). (C) Plots of $\ln \left(A_{0} / A_{t}\right)$ at $400 \mathrm{~nm}$ versus reaction time. (D) Scheme for the hydrogenation reaction catalyzed by PNIPAM-AuNFs at different temperatures. 
catalytic activity for the hydrogenation reaction. In contrast, the characteristic peak of $p$-nitrophenol only decreases slightly within $50 \mathrm{~min}$ in the presence of PNIPAM-AuNFs at $40{ }^{\circ} \mathrm{C}$ (Fig. $4 \mathrm{~B}) \cdot \ln \left(A_{0} / A_{t}\right)$ at $400 \mathrm{~nm}$ is plotted against to the reaction time for both temperatures, where $A_{0}$ and $A_{t}$ are the absorbance at time 0 and $t$. Interestingly, an induction time $\left(t_{0}\right)$ is observed in the initial phase, which is ascribed to the diffusion time of $p$-nitrophenol through the PNIPAM shell. ${ }^{39}$ After the induction time, $\ln \left(A_{0} / A_{t}\right)$ has a linear relationship to the reaction time, indicating that the reduction follows first-order kinetics. ${ }^{40}$ At an extremely low gold concentration of $1.52 \mathrm{mg} \mathrm{L}^{-1}$ in the catalytic reaction solution, the PNIPAM-AuNFs show an apparent rate constant $\left(k_{\text {app }}\right)$ of $1.02 \times 10^{-3} \mathrm{~s}^{-1}$ at $23{ }^{\circ} \mathrm{C}$, which is among the best performing nanocatalysts ever reported (see Table S2, ESI $\dagger$ ). In contrast, by increasing the temperature to $40{ }^{\circ} \mathrm{C}$, a significant drop in the rate constant down to about $10 \%$ is observed, as indicated by a $k_{\text {app }}$ of $1.04 \times 10^{-4} \mathrm{~s}^{-1}$ (Fig. 4C). Obviously, the PNIPAM shell serves as a diffusion barrier for $p$-nitrophenol in the collapsed form resulting in a significant reduction in catalytic activity (Fig. 4D). It is worthy of note that the polymer coating could also have an adverse impact on the catalytic performance as it acts as a physical barrier restricting the access of $p$-nitrophenol to the AuNFs. ${ }^{41}$ There is potential to further optimize the thickness of the PNIPAM coating to increase catalytic performance while retaining high stability and stimulus-responsiveness of the nanohybrids. In addition, the nanocatalyst could be easily recycled by centrifugation but then, a slight decrease of the catalytic activity is observed (Fig. S15, ESI $\dagger$ ).

In summary, we have reported a convenient one-pot strategy for the preparation of PNIPAM-coated AuNF catalysts by combining ARGET ATRP and the reduction of metal ions. The chloroauric anion binding capacity of cationized HSA in combination with the attached ATRP initiators provide an HSA-based macroinitiator allowing polymer growth and nanoparticle formation in a one-step reaction. The sizes and shapes of the resulting AuNFs have been controlled by varying the temperature as well as the molar ratio of the free amino groups from the biopolymer template to the chloroauric anions. The thickness of polymer shell has been adjusted by varying the reaction time. More importantly, the PNIPAM-AuNFs serve as water-soluble and temperature-responsive catalyst for the hydrogenation of $p$-nitrophenol.

The in situ reduction of metal ions and ARGET ATRP has not been combined before for the preparation of polymer-metal nanocomposites. Compared with conventional methods that involve nanoparticle synthesis, purification and post-modification, in situ growth allows the convenient synthesis of polymer-coated metal catalysts without tedious reaction and purification procedures. More significantly, smart polymers formed during the polymerization process provide additional in situ control over the formation of metal nanostructures, which has not been achieved yet. We believe the novel strategy could be expanded to construct other polymer-metal hybrid materials for various applications such as sensing, catalysis, controlled drug delivery, and photothermal therapy.

\section{Conflicts of interest}

There are no conflicts to declare.

\section{Acknowledgements}

The authors acknowledge financial support by the Deutsche Forschungsgemeinschaft (DFG, German Research Foundation) Project number 213555243 SFB 1066 (A06). C. C. is grateful for a doctoral fellowship from Promotionskolleg Pharmaceutical Biotechnology of Ulm University funded by the state of BadenWürttemberg. We thank Christine Rosenauer for her help with the light scattering measurements. We also thank Christopher Synatschke and Nicole Kirsch-Pietz for critically reading the manuscript. Open Access funding provided by the Max Planck Society.

\section{Notes and references}

1 G. Palui, F. Aldeek, W. T. Wang and H. Mattoussi, Chem. Soc. Rev., 2015, 44, 193.

2 D. Kim, S. Park, J. H. Lee, Y. Y. Jeong and S. Jon, J. Am. Chem. Soc., 2007, 129, 7661.

3 P. Xu, X. J. Han, B. Zhang, Y. C. Du and H. L. Wang, Chem. Soc. Rev., 2014, 43, 1349.

4 J. Shan and H. Tenhu, Chem. Commun., 2007, 4580.

5 Y. Ofir, B. Samanta and V. M. Rotello, Chem. Soc. Rev., 2008, 37, 1814.

6 G. I. Dzhardimalieva and I. E. Uflyand, J. Polym. Res., 2018, 25, 255.

7 V. M. Kariuki, J. C. Hoffmeier, I. Yazgan and O. A. Sadik, Nanoscale, 2017, 9, 8330.

8 H. L. Li, Y. Yang, Y. Z. Wang, W. Li, L. H. Bi and L. X. Wu, Chem. Commun., 2010, 46, 3750.

9 W. Wang, X. Yang and H. Cui, J. Phys. Chem. C, 2008, 112, 16348. 10 L. L. Zhao, X. H. Ji, X. J. Sun, J. Li, W. S. Yang and X. G. Peng, J. Phys. Chem. C, 2009, 113, 16645.

11 S. J. Ye, F. Benz, M. C. Wheeler, J. Oram, J. J. Baumberg, O. Cespedes, H. K. Christenson, P. L. Coletta, L. J. C. Jeuken, A. F. Markham, K. Critchley and S. D. Evans, Nanoscale, 2016, 8, 14932.

12 A. J. Wang, Y. F. Li, M. Wen, G. Yang, J. J. Feng, J. Yang and H. Y. Wang, New J. Chem., 2012, 36, 2286.

13 Q. Li, Y. Y. Jiang, R. C. Han, X. L. Zhong, S. Y. Liu, Z. Y. Li, Y. L. Sha and D. S. Xu, Small, 2013, 9, 927.

14 C. Y. Song, B. Y. Yang, W. Q. Chen, Y. X. Dou, Y. J. Yang, N. Zhou and L. H. Wang, J. Mater. Chem. B, 2016, 4, 7112.

15 J. P. Xie, Q. B. Zhang, J. Y. Lee and D. I. C. Wang, ACS Nano, 2008, 2, 2473.

16 D. P. Yang, X. Liu, C. P. Teng, C. Owh, K. Y. Win, M. Lin, X. J. Loh, Y. L. Wu, Z. B. Li and E. Y. Ye, Nanoscale, 2017, 9, 15753.

17 Q. L. Cui, F. He, X. Y. Wang, B. H. Xia and L. D. Li, ACS Appl. Mater. Interfaces, 2013, 5, 213.

18 J. Virkutyte and R. S. Varma, Chem. Sci., 2011, 2, 837.

19 D. Xu, J. J. Gu, W. N. Wang, X. C. Yu, K. Xi and X. D. Jia, Nanotechnology, 2010, 21, 375101. 
20 W. Jakubowski and K. Matyjaszewski, Angew. Chem., Int. Ed., 2006, 45, 4482 .

21 K. Min, H. F. Gao and K. Matyjaszewski, Macromolecules, 2007, 40, 1789.

22 Y. Kwak, A. J. D. Magenau and K. Matyjaszewski, Macromolecules, 2011, 44, 811.

23 A. Simakova, S. E. Averick, D. Konkolewicz and K. Matyjaszewski, Macromolecules, 2012, 45, 6371.

24 W. Bal, M. Sokolowska, E. Kurowska and P. Faller, Biochim. Biophys. Acta, 2013, 1830, 5444.

25 S. Chakrabortty, B. K. Agrawalla, A. Stumper, N. M. Veg, S. Fischer, C. Reichardt, M. Kogler, B. Dietzek, M. Feuring-Buske, C. Buske, S. Rau and T. Weil, J. Am. Chem. Soc., 2017, 139, 2512.

26 Y. Z. Wu, S. Chakrabortty, R. A. Gropeanu, J. Wilhelmi, Y. Xu, K. S. Er, S. L. Kuan, K. Koynov, Y. Chan and T. Weil, J. Am. Chem. Soc., 2010, 132, 5012.

27 Y. Z. Wu, A. Ermakova, W. N. Liu, G. Pramanik, T. M. Vu, A. Kurz, L. McGuinness, B. Naydenov, S. Hafner, R. Reuter, J. Wrachtrup, J. Isoya, C. Fortsch, H. Barth, T. Simmet, F. Jelezko and T. Weil, Adv. Funct. Mater., 2015, 25, 6576.

28 D. Y. W. Ng, Y. Z. Wu, S. L. Kuan and T. Weil, Acc. Chem. Res., 2014, 47, 3471.

29 R. A. Alvarez-Puebla, R. Contreras-Caceres, I. Pastoriza-Santos, J. Perez-Juste and L. M. Liz-Marzan, Angew. Chem., Int. Ed., 2009, 48, 138.
30 M. Tagliazucchi, M. G. Blaber, G. C. Schatz, E. A. Weiss and I. Szleifert, ACS Nano, 2012, 6, 8397.

31 S. Maji, B. Cesur, Z. Y. Zhang, B. G. De Geest and R. Hoogenboom, Polym. Chem., 2016, 7, 1705.

32 R. Contreras-Caceres, A. Sanchez-Iglesias, M. Karg, I. PastorizaSantos, J. Perez-Juste, J. Pacifico, T. Hellweg, A. FernandezBarbero and L. M. Liz-Marzan, Adv. Mater., 2008, 20, 1666.

33 B. S. Li, D. M. Smilgies, A. D. Price, D. L. Huber, P. G. Clem and H. Y. Fan, ACS Nano, 2014, 8, 4799.

34 J. L. Zhang, M. X. Zhang, K. J. Tang, F. Verpoort and T. L. Sun, Small, 2014, 10, 32.

35 X. Y. Zhu, Z. S. Lv, J. J. Feng, P. X. Yuan, L. Zhang, J. R. Chen and A. J. Wang, J. Colloid Interface Sci., 2018, 516, 355.

36 Z. S. Lv, X. Y. Zhu, H. B. Meng, J. J. Feng and A. J. Wang, J. Colloid Interface Sci., 2019, 538, 349.

37 Y. Yu, W. Q. Xiao, T. T. Zhou, P. Zhang, C. Yan and Z. J. Zheng, Mater. Chem. Front., 2017, 1, 482.

38 X. F. Zhang, X. Y. Zhu, J. J. Feng and A. J. Wang, Appl. Surf. Sci., 2018, 428, 798.

39 Z. Chen, Z. M. Cui, C. Y. Cao, W. D. He, L. Jiang and W. G. Song, Langmuir, 2012, 28, 13452.

40 S. Wunder, Y. Lu, M. Albrecht and M. Ballauff, ACS Catal., 2011, 1, 908.

41 Z. Q. Niu and Y. D. Li, Chem. Mater., 2014, 26, 72. 